\title{
EULAR recommendations for the treatment of systemic sclerosis: a report from the EULAR Scleroderma Trials and Research group (EUSTAR)
}

\author{
0 Kowal-Bielecka, ${ }^{1}$ R Landewé, ${ }^{2}$ J Avouac, ${ }^{3}$ S Chwiesko, ${ }^{1}$ I Miniati, ${ }^{4}$ L Czirjak, ${ }^{5}$ \\ P Clements, ${ }^{6}$ C Denton, ${ }^{7}$ D Farge, ${ }^{8}$ K Fligelstone,${ }^{9}$ I Földvari, ${ }^{10}$ D E Furst, ${ }^{6}$ U Müller- \\ Ladner, ${ }^{11}$ J Seibold, ${ }^{12}$ R M Silver, ${ }^{13}$ K Takehara, ${ }^{14}$ B Garay Toth, ${ }^{15}$ A Tyndall, ${ }^{16}$ \\ $\mathrm{G}$ Valentini, ${ }^{17} \mathrm{~F}$ van den Hoogen, ${ }^{18} \mathrm{~F}$ Wigley, ${ }^{19} \mathrm{~F}$ Zulian, ${ }^{20}$ Marco Matucci-Cerinic, ${ }^{4}$ \\ and the EUSTAR co-authors
}

\begin{abstract}
- Additional supplementary material and tables 3 and 4 are published online only at http:// ard.bmj.com/content/vol68/ issue 5

For numbered affiliations see end of article

Correspondence to: Dr M Matucci-Cerinic, Department of BioMedicine and Surgery, Division of Rheumatology, University of Florence, Villa Monna Tessa, viale G Pieraccini 18, 50134 Florence, Italy; cerinic@unifi.it
\end{abstract}

Accepted 10 December 2008 Published online first

19 January 2009

\section{ABSTRACT}

Purpose: The optimal treatment of systemic sclerosis (SSc) is a challenge because the pathogenesis of SSc is unclear and it is an uncommon and clinically heterogeneous disease affecting multiple organ systems. The aim of the European League Against Rheumatism (EULAR) Scleroderma Trials and Research group (EUSTAR) was to develop evidence-based, consensus-derived recommendations for the treatment of SSc.

Methods: To obtain and maintain a high level of intrinsic quality and comparability of this approach, EULAR standard operating procedures were followed. The task force comprised 18 SSc experts from Europe, the USA and Japan, two SSc patients and three fellows for literature research. The preliminary set of research questions concerning SSc treatment was provided by 74 EUSTAR centres.

Results: Based on discussion of the clinical research evidence from published literature, and combining this with current expert opinion and clinical experience, 14 recommendations for the treatment of SSc were formulated. The final set includes the following recommendations: three on SSc-related digital vasculopathy (Raynaud's phenomenon and ulcers); four on SSc-related pulmonary arterial hypertension; three on SSc-related gastrointestinal involvement; two on scleroderma renal crisis; one on SSc-related interstitial lung disease and one on skin involvement. Experts also formulated several questions for a future research agenda.

Conclusions: Evidence-based, consensus-derived recommendations are useful for rheumatologists to help guide treatment for patients with SSc. These recommendations may also help to define directions for future clinical research in SSc.

Systemic sclerosis (SSc; scleroderma) affects the skin and multiple internal organs leading, eventually, to fibrosis. ${ }^{1}$ The European League against Rheumatism (EULAR) and the EULAR Scleroderma Trials and Research group (EUSTAR) have acknowledged the need for evidence-based recommendations to be used in clinical practice. Following EULAR's standard operating procedures, an ad hoc expert committee was established by EULAR and EUSTAR. ${ }^{2}$

The present recommendations discuss the drug treatments, based on a combination of evidence and consensus, which, in the opinion of the community of SSc specialists (EUSTAR members and invited experts), were considered most important in the therapy of SSc. The appropriate management of SSc patients is complex and includes issues such as early diagnosis of internal organ involvement, identification of patients who are at risk of progressive disease and non-pharmacological treatments, all of which are beyond the scope of this paper. Moreover, there are new promising therapies, as well as some established treatments, which have not yet been studied extensively enough to be included in the present set of recommendations but might be helpful in individual SSc patients. Some of these treatments are included in a comment section or research agenda. The absence of a positive recommendation cannot thus be taken as a recommendation against use or that the agent has proved to be unhelpful/ dangerous.

The main aim of these recommendations is to provide guidance to rheumatologists and practitioners to approach and choose the treatment for SSc patients. No recommendations regarding contraindications or what should not be done are included for procedural and other reasons.

Likewise, cost considerations, despite their importance, were not included in these considerations, as costs vary widely across countries and no uniform base case cost could be derived.

These recommendations are not meant to replace the physician's clinical judgement. They should be viewed in terms of the clinician's understanding of the individual patient and the clinician's judgement of the balance between the efficacy and toxicity of a treatment for a specific person. Although some treatment-related toxicities are mentioned in the text of recommendations and/or in the following comments, this is the responsibility of the physician to recognise and monitor all possible toxicities/side effects according to the information supplied by the producer and all other available sources.

Throughout this paper, the specific recommendation is followed by the evidence supporting the recommendation. It should be realised that the committee utilised the evidence in each case and when evidence was not sufficient, supplemented it by the consensus-derived expert opinion to arrive at specific recommendations. 
Consistent with EULAR guidelines for the generation of recommendations, only data up to a defined time point (December 2006) are included in the analysis. If new data become available later, they will be included in the next update, which is also a regular feature of EULAR recommendations.

\section{METHODS}

To obtain and maintain a high level of intrinsic quality and comparability, EULAR standardised operating procedures were followed. ${ }^{2}$ The detailed methodology for developing EULAR/ EUSTAR recommendations on the treatment of SSc has been reported previously. ${ }^{3}$ Briefly, the task force included $18 \mathrm{SSc}$ experts from Europe (two of them paediatric rheumatologists), the USA and Japan, two SSc patients from the Federation of the European Scleroderma Associations (FESCA) and three fellows for literature research. The preliminary set of research questions concerning SSc treatment was provided by 74 EUSTAR centres. After a process of aggregation and data reduction by a modified Delphi technique, the experts selected the final set of 26 questions for the systematic literature research. Retrieved clinical trial publications were evaluated using the Jadad classification, ${ }^{4}$ and the level of evidence was graded from Ia to IV. ${ }^{5}$ Outcome data for efficacy and adverse events were abstracted and effect size (ES), number needed to treat (NNT) and number needed to harm were calculated when appropriate.

\section{RESULTS}

\section{Evidence-based approach}

Out of 5421 publications identified, 281 were included in the final analysis.

The methodology, including the selection of research questions and literature search strategy and the results of systematic literature research are presented separately. ${ }^{3}$

\section{Experts' opinion approach}

The final set of recommendations, grouped according to organ systems and the future research agenda are summarised in table 1 and box 1 , respectively.

The evidence that there are few high-quality trials in SSc prompted the experts also to include information concerning the highest level of evidence based upon which a particular recommendation was formulated.

Moreover, the experts decided to formulate, in addition to the main recommendations, several comments concerning medications or therapies addressed in research questions, on which at present neither literature-based evidence nor clinical experience allowed precise recommendations to be made, see table 2 .

All recommendations and appropriate comments were accepted unanimously.

\section{Final recommendations (propositions)}

\section{SSc-related digital vasculopathy (Raynaud's phenomenon, digital} ulcers)

1. A meta-analysis on dihydropiridine-type calcium antagonists and one meta-analysis on prostanoids indicate that nifedipine and intravenous iloprost reduce the frequency and severity of SSc-related Raynaud's phenomenon (SSc-RP) attacks.

Dihydropiridine-type calcium antagonists, usually oral nifedipine, should be considered for first-line therapy for SSc-RP, and intravenous iloprost, or other available intravenous prostanoids, should be considered for severe SSc-RP.

One meta-analysis, including eight randomised controlled trials (RCT; seven with nifedipine and one with nicardipine) $)^{6-13}$ with 109 SSc patients involved, indicates that dihydropiridinetype calcium antagonists reduce the frequency and severity of ischaemic attacks in SSc-RP. ${ }^{14}$ The weighted mean difference (WMD) of all calcium antagonists versus placebo (six trials) for the reduction in the number of ischaemic attacks over a 2-week period was 8.3 (95\% CI 0.9 to 15.7). When five RCT evaluating nifedipine (10-20 mg three times a day) versus placebo were analysed separately, the reduction was greater with a WMD of 10.2 (95\% CI 0.3 to 20.1$)$.

The standardised mean difference of all calcium antagonists versus placebo (three trials) for the reduction in the severity of ischaemic attacks was 0.7 (95\% CI 0.2 to 1.2$)$. Clinically, this effect can be compared to a reduction in severity of $2.3 \mathrm{~cm}$ on a $10-\mathrm{cm}$ visual analogue scale, or a more than $35 \%$ improvement compared with placebo. Again, the effect of nifedipine alone versus placebo (two trials) was greater (standardised mean difference $1.0 ; 95 \%$ CI 0.2 to 1.7 ).

Two randomised placebo-controlled trials in patients with mixed forms of Raynaud's phenomenon (RP) evaluated the efficacy of diltiazem. Those studies, which were not in the meta-analysis because they did not include an analysis on SSc patients only, gave contradictory results. ${ }^{15} 16$

A second meta-analysis, which included the results of five RCT with intravenous iloprost, one RCT with oral iloprost and one RCT with oral cisaprost, ${ }^{17-23}$ with 332 SSc patients in total, indicates that iloprost is effective in reducing the frequency and severity of SSc-RP. ${ }^{24}$ Iloprost, given intravenously $(0.5-3 \mathrm{ng} / \mathrm{kg}$ per minute for 3-5 consecutive days sequentially) or orally (50$150 \mu \mathrm{g}$ twice a day) significantly reduced the frequency of ischaemic attacks, and improved the RP severity score in comparison with placebo (WMD 17.5; 95\% CI 15.7 to 19.2 and WMD 0.7; 95\% CI 0.3 to 1.1, respectively). Oral prostanoids seem to be generally less effective than intravenous iloprost in the treatment of SSc-RP, although some beneficial effects could be seen with higher doses. ${ }^{17} 1924-27$

Two RCT comparing intravenous iloprost $(0.5-2 \mathrm{ng} / \mathrm{kg}$ per minute for 3-5 days, every 6-8 weeks) with nifedipine (30$60 \mathrm{mg} /$ day) indicate that iloprost is only slightly superior to nifedipine in improving symptoms of SSc-RP. ${ }^{10}{ }^{28}$

In view of costs and feasibility, the experts recommended that calcium antagonists are first-line therapy in the treatment of SSc-RP. Intravenous prostanoids are recommended when calcium antagonists have failed.

It should be recognised that, in addition to calcium antagonists and prostanoids, there are many other therapies that are in use for the treatment of SSc-RP, see supplement available online only.

As both types of drugs may induce side effects of vascular origin, the experts recommend particular attention if prostanoids are combined with calcium antagonists.

2. Two RCT indicate that intravenous prostanoids (particularly intravenous iloprost) are efficacious in healing digital ulcers in patients with SSc. Intravenous prostanoids (in particular iloprost) should be considered in the treatment of active digital ulcers in patients with SSc.

Intravenous iloprost $(0.5-2 \mathrm{ng} / \mathrm{kg}$ per minute for $3-5$ consecutive days) significantly reduced the number of digital ulcers in comparison with placebo in one small RCT (Jadad score 3), and improved digital ulcer healing in another RCT (Jaded score 4) including 73 SSc patients with active digital ulcers ( $p=0.06$ vs placebo for $50 \%$ improvement). ${ }^{21}{ }^{22}$ In addition, two RCT comparing intravenous iloprost with oral nifedipine suggest that both medications have a beneficial effect on digital ulcer 
healing, but the number of patients with digital ulcers in both trials was small. ${ }^{10} 28$

Moreover, intravenous epoprostenol, administered continuously for severe SSc-related pulmonary arterial hypertension (SSc-PAH), revealed a tendency towards a reduction in the number of new digital ulcers (by $50 \%$ ). ${ }^{29}$

3. Bosentan has no confirmed efficacy in the treatment of active digital ulcers in SSc patients. Bosentan has confirmed efficacy in two high-quality RCT to prevent digital ulcers in diffuse SSc patients, in particular in those with multiple digital ulcers.

Bosentan should be considered in diffuse SSc with multiple digital ulcers, after failure of calcium antagonists and, usually, prostanoid therapy.

Bosentan, a dual endothelin receptor antagonist (ERA), was evaluated in two placebo-controlled RCT (RAPIDS-1 and RAPIDS-2) (Jadad score 5) involving $210 \mathrm{SSc}$ patients in total. ${ }^{30-32}$ Bosentan, at an oral dose of $62.5 \mathrm{mg}$ twice a day for 4 weeks followed by $125 \mathrm{mg}$ twice a day for another 12 weeks, significantly reduced the number of new digital ulcers by $48 \%$ compared with placebo (ES $0.4 ; 95 \%$ CI 0.0 to 0.8 ). ${ }^{31}$ The efficacy of bosentan in preventing new digital ulcer formation was corroborated by the results of the recent RAPIDS-2 study, which was performed in SSc patients with active digital ulcers (this is a population considered to be at high risk of peripheral digital necrosis) (mean placebo-adjusted improvement 0.7 (39\%) and $0.8(30 \%)$ new ulcers per patient over 12 and 24 weeks, respectively; $\mathrm{p}<0.05$ vs placebo for both comparisons). ${ }^{31}{ }^{22}$ Posthoc subgroup analysis of RAPIDS-1 suggested that the highest effect of bosentan was found in diffuse SSc $(61 \%$ reduction over 16 weeks; $p=0.011$ vs placebo), especially in diffuse SSc with active digital ulcers (67\%; $p<0.001$ vs placebo), whereas in limited SSc the mean reduction was $38 \%$ when considering the entire population and $30 \%$ if limited to patients with active digital ulcers. ${ }^{30}$ It is anticipated that the results of RAPIDS-2, when published, will add new information concerning the efficacy of bosentan in the prevention of digital ulcers in SSc subsets.

Neither trial indicated that bosentan is superior to placebo in the healing of SSc-related active digital ulcers, as evaluated by the time to complete or partial healing of digital ulcers present at baseline, the time to healing of all digital ulcers, or the percentage of patients with complete digital ulcer healing ( $p>0.05$ vs placebo for all comparisons). ${ }^{30-32}$ The beneficial effect on new digital ulcer formation was accompanied by a significant improvement in overall hand function (specific health assessment questionnaire (HAO) score ES $0.4 ; 95 \%$ CI 0.0 to 0.8 ) in RAPIDS- 1 , and a significant improvement in the Scleroderma-HAO dressing domain $(p=0.03)$ in RAPIDS-2.

As discussed above, intravenous iloprost and epoprostenol were shown to improve the healing of active digital ulcers. ${ }^{102122} 2829$ Calcium antagonists, efficacious in the treatment of SSc-RP, have been studied less extensively with respect to the prevention and healing of digital ulcers in SSc. The results of two RCT, with low numbers of patients with digital ulcers, suggest a comparable efficacy of calcium antagonists and intravenous iloprost in healing active digital ulcers in SSc. ${ }^{10} 28$ In a small RCT with $10 \mathrm{SSc}$ patients, nifedipine (30 mg/day) reduced both the number of patients with new digital ulcers and the total number of new digital ulcers by $50 \%$ compared with placebo over a 6-week period (NNT 3.3 for preventing new digital ulcers). ${ }^{12}$ The available evidence concerning calcium antagonists and prostanoids in the prevention of new digital ulcers in SSc patients is far less comprehensive and robust than that of bosentan, but their toxicity pattern is milder, and longterm clinical experience suggests a good safety profile.

There are two major concerns related to the use of bosentan and other ERA: potential liver injury and teratogenicity. ${ }^{33} 34$ Hormonal contraceptives may not be reliable if co-administered with bosentan, because bosentan may reduce their efficacy by interference with the cytochrome P450 system. ${ }^{35}$

\section{SSc-PAH}

4. Two high-quality RCT indicate that bosentan improves exercise capacity, functional class and some haemodynamic measures in pulmonary arterial hypertension (PAH). Bosentan should be strongly considered to treat SSc-PAH.

The efficacy of ERA in the treatment of PAH was analysed in a meta-analysis of four RCT evaluating bosentan and one RCT evaluating sitaxentan ${ }^{36-41}$ (see supplementary material available online only). The results of this meta-analysis refer mainly to patients with idiopathic $\mathrm{PAH}$, who constituted the vast majority (mean 67\%, range 53-89\%) of patients recruited in the studies analysed. In SSc-PAH, known to have a worse prognosis than idiopathic $\mathrm{PAH}$, only bosentan has been studied extensively, including data concerning survival in SSc-PAH patients exclusively.

Two high-quality (Jadad score 5) placebo-controlled RCT showed that bosentan (62.5 mg twice a day for 4 weeks, followed by $125-250 \mathrm{mg}$ twice a day) significantly improved the 6-minute walk test (6MWT) after 12 and 16 weeks in a heterogeneous population of PAH patients, see supplementary table 3 available online only. ${ }^{36}{ }^{37}$ An improvement in exercise capacity coincided with an improvement in the New York Heart Association (NYHA)/World Health Organization (WHO) functional class (NNT 3 and NNT 7.7 to 14.3, respectively), dyspnoea score (ES 1.6; 95\% CI 1.2 to 1.9 and ES 4.5; 95\% CI 3.8 to 5.1 for bosentan dosages of $250 \mathrm{mg} /$ day and $500 \mathrm{mg} /$ day, respectively) and haemodynamic measures, see supplementary table 3 available online only. ${ }^{36} 3742$

A subanalysis of 66 patients with connective tissue disease (CTD)-related PAH (CTD-PAH) included in the above two RCT (79\% were SSc patients) revealed a placebo-adjusted improvement in 6MWT of $22 \mathrm{~m}$ in favour of bosentan (ES 0.3; $95 \%$ CI -0.2 to 0.8$){ }^{43}$

Analysis of the two pivotal RCT and their long-term extension studies suggested that bosentan may improve survival in SSc-PAH in comparison with historic controls (1,2 and 3-year survival $82 \%, 67 \%$ and $64 \%$, respectively, vs $45 \%, 35 \%$ and $28 \%){ }^{44}$ Similarly, Williams et a ${ }^{45}$ demonstrated that SSc-PAH patients receiving bosentan (in addition to standard therapy consisting of diuretics, digoxin, oxygen, warfarin and, if clinically indicated, prostanoids) had a significantly better survival ( $81 \%$ at 1 year, $71 \%$ at 2 years) than a historic comparator group of SSc-PAH patients treated with standard therapy including prostanoids (survival $68 \%$ and $47 \%$ at 1 and 2 years, respectively; $p=0.016$ ).

On the basis of the results of RCT, bosentan was recommended in the current guidelines of the American College of Chest Physicians (ACCP) for the treatment of severe $\mathrm{PAH}$ (WHO class III/IV). ${ }^{46}$

5. Two high-quality RCT indicate that sitaxentan improves exercise capacity, functional class and some haemodynamic measures in PAH. At present, sitaxentan may also be considered to treat SSc-PAH.

Two high-quality (Jadad score 4) RCT (STRIDE-1 and STRIDE-2) including 423 patients with different forms of $\mathrm{PAH}$, among which $63(15 \%)$ had SSc-PAH, indicate that 
sitaxentan (a selective $\mathrm{ET}_{\mathrm{A}}$ endothelin receptor antagonist), administered orally at a dose of $100 \mathrm{mg} /$ day and $300 \mathrm{mg}$ /day for 12 to 18 weeks, significantly improved exercise capacity and haemodynamics, ${ }^{39}{ }^{47}$ see supplementary table 3 available online only. Accordingly, sitaxentan (100 mg/day and $300 \mathrm{mg} /$ day) improved NYHA functional class compared with placebo (NNT 7 for both doses assessed over 12 weeks). ${ }^{39}$ The improvement was even greater in a STRIDE-1 subgroup of PAH patients being in WHO class III or IV, suggesting that patients with more severe PAH may achieve the greatest benefit from sitaxentan therapy, ${ }^{48}$ see supplementary table 3 available online only. In view of the comparable efficacy of the two sitaxentan regimens and the fact that the higher dose was associated with greater toxicity (discussed below), sitaxentan at a dose of $100 \mathrm{mg} /$ day is suggested in the treatment of PAH.

No studies or specific subgroup analyses investigating the efficacy of sitaxentan in SSc-PAH have been published. A subanalysis of both pivotal trials combining the 110 patients with CTD-PAH, of whom 63 (57\%) had SSc-PAH, showed that $100 \mathrm{mg}$ /day revealed a similar improvement in the 6MWT as in the overall STRIDE-1 study population (ES 0.3 ; $95 \%$ CI -0.2 to 0.8 for sitaxentan vs placebo). ${ }^{49}$ One-year survival in 42 CTD$\mathrm{PAH}$ patients receiving sitaxentan in open-label studies was significantly better than in 25 CTD-PAH patients treated with bosentan (98\% vs 79\%; $\mathrm{p}<0.001$ ), although the effects on $6 \mathrm{MWT}$ and functional class were not different comparing the two drugs. ${ }^{50}$

In view of its comparable efficacy and its similar toxicity profile, experts considered sitaxsentan as an alternative for bosentan in patients with SSc-PAH. An open-label extension of STRIDE-2 suggested that sitaxentan (100 mg/day) may be safer than bosentan $(250 \mathrm{mg} /$ day) with regard to the frequency of liver test abnormalities ( $3 \%$ of the sitaxentan group vs $18 \%$ of the bosentan group; $\mathrm{p}<0.03$ ) and premature discontinuation, either related to hepatotoxicity ( $0 \%$ vs $14 \%$ for sitaxentan vs bosentan) or overall ( $20 \%$ vs $57 \%$ for sitaxentan vs bosentan; $\mathrm{p}<0.001){ }^{50}$ Moreover, sitaxentan $100 \mathrm{mg}$ /day improved the clinical status in more than one-third of PAH patients in whom bosentan was ineffective. ${ }^{51}$

Sitaxentan, as other ERA, is potentially teratogenic and may reduce the efficacy of hormonal contraceptive therapy.

6. One high-quality RCT indicates that sildenafil improves exercise capacity, functional class and some haemodynamic measures in PAH.

Sildenafil may be considered to treat SSc-PAH.

One high-quality RCT (Jadad score 5) has demonstrated that sildenafil (a selective type 5 phosphodiesterase inhibitor), given orally at a dose of $20 \mathrm{mg}, 40 \mathrm{mg}$ or $80 \mathrm{mg}$ three times a day, significantly improved the 6MWT result, functional class and haemodynamics over a 12 -week period in PAH of different origin, ${ }^{52}$ see supplementary table 4 available online only.

Another RCT (Jadad score 5), involving $26 \mathrm{PAH}$ patients (of whom two had SSc-PAH) indicated that sildenafil (50 mg twice a day for 4 weeks followed by $50 \mathrm{mg}$ three times a day) was comparable to, or even better than, bosentan in improving the 6MWT, Borg dyspnoea score and cardiac index. ${ }^{41}$ The improvement in exercise capacity was maintained to at least 1 year. ${ }^{52}$

In a subgroup of 84 patients with CTD-PAH (including 38 SSc-PAH patients) sildenafil significantly improved walking distance $(p<0.05$ for $60 \mathrm{mg} /$ day and $120 \mathrm{mg} /$ day), functional class (NNT from 4.0 to 2.9, depending on the sildenafil dose), mean pulmonary artery pressure and pulmonary vascular reserve $(p<0.05$ for $60 \mathrm{mg} /$ day for both) in comparison with placebo. $^{53}$
Sildenafil has been approved by the US Food and Drug Administration (FDA) for the treatment of $\mathrm{PAH}$ patients in WHO functional classes II, III and IV. ${ }^{46}$ The experts indicated that, compared with bosentan, the amount of data confirming the efficacy and safety of sildenafil in SSc-PAH was sparse. Therefore, at present, sildenafil should be considered for the treatment of SSc-PAH patients in whom bosentan has been ineffective, or can not be used for safety reasons.

7. One high-quality RCT indicates that continuous intravenous epoprostenol improves exercise capacity, functional class and haemodynamic measures in SSc-PAH. Sudden drug withdrawal may be life threatening.

Intravenous epoprostenol should be considered for the treatment of patients with severe SSc-PAH.

One RCT (Jadad score 3), involving 111 SSc-PAH patients, showed that epoprostenol (continuous intravenous infusion, starting dose $2 \mathrm{ng} / \mathrm{kg}$ per minute and increased based on clinical symptoms and tolerability) in combination with conventional therapy (diuretics, oral anticoagulants, oxygen and glycosides), improves exercise capacity, functional status and haemodynamic measures in SSc-PAH, compared with conventional therapy. ${ }^{29}$ The median 6MWT distance improved by $108 \mathrm{~m}$ (95\% CI $55 \mathrm{~m}$ to $180 \mathrm{~m}$; p < 0.001 ; epoprostenol vs control group), NYHA functional class improved in 21 (38\%) patients treated with epoprostenol and none in the control group (NNT 2.7) and the Borg dyspnoea index and the dyspnoea fatigue score also improved significantly. The beneficial haemodynamic effects of epoprostenol included a statistically significant decrease in pulmonary vascular resistance, mean pulmonary artery pressure and right atrial pressure, as well as a significant increase in cardiac index.

Based on the results of RCT and two large long-term observational studies, which have documented an improvement in survival of patients with idiopathic PAH treated with epoprostenol, ${ }^{54}{ }^{55}$ intravenous epoprostenol has been approved by the FDA for the treatment of severe (WHO class III or IV) PAH.

As a result of a very short half-life, epoprostenol is administered through a permanent indwelling central venous catheter, which may favour adverse events: infections, pneumothorax and haemorrhage. ${ }^{29}$ Sudden disruption/withdrawal of intravenous eporostenol (due to catheter/vein thrombosis and/ or patient's decision) may lead to life-threatening PAH rebound. Epoprostenol is contraindicated in severe left ventricular dysfunction and if symptoms of pulmonary oedema develop during epoprostenol dose initiation, which may be associated with pulmonary veno-occlusive disease. ${ }^{56}$ Based on overall riskto-benefit considerations, and in agreement with the current ACCP guidelines, experts recommend intravenous eporostenol as the treatment of choice in severe, therapy-resistant SSc$\mathrm{PAH}{ }^{46}$

Although not included in the text of the present recommendations, other prostacyclin analogues are available and approved for treatment of $\mathrm{PAH}$, see supplementary material available online only. ${ }^{57-59}$

\section{SSc-related skin involvement}

8. Two RCT have shown that methotrexate improves skin score in early diffuse SSc. Positive effects on other organ manifestations have not been established.

Methotrexate may be considered for treatment of skin manifestations of early diffuse SSc. 
Table 1 The final set of 14 recommendations based on both evidence from the literature and expert opinion

\begin{tabular}{|c|c|c|c|c|}
\hline No & \multicolumn{2}{|c|}{ Recommendation } & $\begin{array}{l}\text { Strength of } \\
\text { recommendation }\end{array}$ & References \\
\hline \multirow[t]{5}{*}{ I } & \multicolumn{4}{|c|}{ SSc-related digital vasculopathy (RP, digital ulcers) } \\
\hline & \multirow[t]{2}{*}{1} & $\begin{array}{l}\text { A meta-analysis on dihydropiridine-type calcium antagonists and one meta-analysis on prostanoids indicate that nifedipine } \\
\text { and intravenous iloprost reduce the frequency and severity of SSc-RP attacks }\end{array}$ & A & 1424 \\
\hline & & $\begin{array}{l}\text { Dihydropiridine-type calcium antagonists, usually oral nifedipine, should be considered for first-line therapy for SSc-RP, and } \\
\text { intravenous iloprost, or other available intravenous prostanoids for severe SSc-RP }\end{array}$ & & \\
\hline & 2 & $\begin{array}{l}\text { Two RCT indicate that intravenous prostanoids (particularly intravenous iloprost) are efficacious in healing digital ulcers in } \\
\text { patients with SSc. Intravenous prostanoids (in particular iloprost) should be considered in the treatment of active digital } \\
\text { ulcers in patients with SSc }\end{array}$ & A & 2122 \\
\hline & 3 & $\begin{array}{l}\text { Bosentan should be considered in diffuse SSc with multiple digital ulcers after failure of calcium antagonists and, usually, } \\
\text { prostanoid therapy }\end{array}$ & & \\
\hline \multirow[t]{5}{*}{ II } & \multicolumn{4}{|c|}{ SSc-PAH } \\
\hline & 4 & $\begin{array}{l}\text { Two high-quality RCT indicate that bosentan improves exercise capacity, functional class and some haemodynamic } \\
\text { measures in PAH. Bosentan should be strongly considered to treat SSc-PAH }\end{array}$ & $\mathrm{A} / \mathrm{B}$ & 3637 \\
\hline & 6 & Sildenafil may be considered to treat SSc-PAH & & \\
\hline & \multirow[t]{2}{*}{7} & $\begin{array}{l}\text { One high-quality RCT indicates that continuous intravenous epoprostenol improves exercise capacity, functional class and } \\
\text { haemodynamic measures in SSc-PAH. Sudden drug withdrawal may be life threatening }\end{array}$ & A & 29 \\
\hline & & Intravenous epoprostenol should be considered for the treatment of patients with severe SSc-PAH & & \\
\hline \multirow[t]{3}{*}{ III } & \multicolumn{4}{|c|}{ SSc-related skin involvement } \\
\hline & \multirow[t]{2}{*}{8} & $\begin{array}{l}\text { Two RCT have shown that methotrexate improves skin score in early diffuse SSc. Positive effects on other organ } \\
\text { manifestations have not been established }\end{array}$ & A & 6061 \\
\hline & & Methotrexate may be considered for treatment of skin manifestations of early diffuse SSc & & \\
\hline \multirow[t]{2}{*}{ IV } & \multicolumn{2}{|r|}{ SSC-ILD } & & \\
\hline & 9 & $\begin{array}{l}\text { In view of the results from two high-quality RCT and despite its known toxicity, cyclophosphamide should be considered for } \\
\text { treatment of SSc-ILD }\end{array}$ & A & 6263 \\
\hline V & \multicolumn{2}{|r|}{ 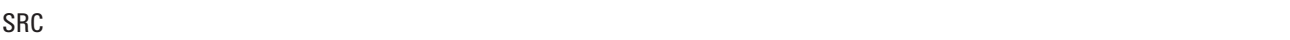 } & & \\
\hline VI & 14 & $\begin{array}{l}\text { Despite the lack of specific RCT, experts believe that, when malabsorption is caused by bacterial overgrowth, rotating } \\
\text { antibiotics may be useful in SSc patients }\end{array}$ & $\mathrm{D}$ & \\
\hline
\end{tabular}

ACE, angiotensin-converting enzyme; GORD, gastro-oesophageal reflux disease; PAH, pulmonary arterial hypertension; PPI, proton pump inhibitor; RCT, randomised controlled trial; $\mathrm{RP}$, Raynaud's phenomenon; SRC, scleroderma renal crisis; SSc, systemic sclerosis; SSc-ILD, SSc-related interstitial lung disease; SSc-PAH, SSc-related pulmonary arterial hypertension; SSc-RP, SSC-related Raynaud's phenomenon.

In one RCT (Jadad score 3), involving 29 SSc patients with diffuse SSc or limited SSc (mean duration of skin involvement 3.2 years), methotrexate (intramuscularly at a dose of $15 \mathrm{mg}$ / week for 24 weeks) showed a trend towards improvement of the total skin score $\left(p=0.06\right.$ vs placebo) ${ }^{60}$

In the second RCT (Jadad score 5), involving 73 patients with early diffuse SSc, methotrexate, given orally at a dose of $10 \mathrm{mg}$ per week for 12 months, decreased the University of California Los Angeles skin score (ES $0.5,95 \%$ CI 0.0 to 1.0 ) and the modified Rodnan skin score (ES $0.5 ; 95 \%$ CI 0.0 to 0.9 ) compared with placebo in an intention-to-treat analysis. Eleven out of 36 patients (31\%) in the placebo group and 12 out of 35 patients (34\%) in the methotrexate group dropped out before study completion, mainly due to treatment inefficacy. There were few premature discontinuations due to adverse events (number needed to harm 16 and 34.5 in both RCT, respectively). ${ }^{60}{ }^{61}$ There were no significant differences in the mortality rate (three vs seven; $\mathrm{p}<0.18$ ), although the trend was in favour of methotrexate. ${ }^{61}$ Safety concerns associated with methotrexate include liver toxicity, pancytopenia, its potential teratogeneity and, possibly, the induction of lung injury/ interstitial lung disease. ${ }^{60} 81$

It should be recognised that cyclophosphamide has also been shown, in RCT, to improve skin changes in SSc patients, and other agents such as mycophenolate mofetil, azathioprine or ciclosporine A are used to treat skin involvement, although their efficacy has not been studied so extensively, ${ }^{62}$ see also table 2 .

\section{Scleroderma interstitial lung disease}

9. In view of the results from two high-quality RCT and despite its known toxicity, cyclophosphamide should be considered for the treatment of SSc-related interstitial lung disease (SSc-ILD).

The efficacy and safety of cyclophosphamide in the treatment of SSc-ILD was evaluated in two high-quality (Jadad score 5) RCT. $^{62}{ }^{63}$ The first trial, involving 158 SSc patients with active alveolitis, demonstrated that cyclophosphamide given orally at a dose of $1-2 \mathrm{mg} / \mathrm{kg}$ per day improved lung function tests, dyspnoea score and quality of life over 12 months compared 


\section{Box 1 Research agenda}

1. Evaluation of the efficacy and safety of cyclophosphamide in the treatment of early diffuse SSc

2. Evaluation of the efficacy and safety of mycophenolate mofetil and azathioprine in the treatment of SSc

3. Evaluation of the efficacy and safety of sildenafil in the treatment of SSc-RP and digital ulcers

4. Evaluation of the efficacy and safety of ACE inhibitors in the prevention of SRC

5. Evaluation of calcium antagonists in the prevention of SScPAH

with placebo. The placebo-corrected mean (95\% CI) improvement in the forced vital capacity and the total lung capacity was $2.5 \%(0.3 \%$ to $4.8 \%)$ and $4.1 \%(0.5 \%$ to $7.7 \%)$, respectively $(p<0.03$ for both measures). Cyclophosphamide did not increase the lung diffusing capacity for carbon monoxide. Cyclophosphamide improved the transitional dyspnoea index (mean 1.4 (SE 0.2), whereas this index deteriorated in the placebo group (mean 1.5 (SE 0.4); $<<0.001$ for between-group difference). Cyclophosphamide also improved the HAO disability index, and the vitality and health-transition domains of the Short-Form 36 ( $p<0.05$ vs placebo for both measures). ${ }^{62}$

The second trial evaluated cyclophosphamide (intravenously at a dose of $600 \mathrm{mg} / \mathrm{m}^{2}$ per month) compared with placebo in 45 SSc patients with SSc-ILD. Active treatment included six infusions of cyclophosphamide given at 4-week intervals followed by oral azathioprine $(2.5 \mathrm{mg} / \mathrm{kg}$ per day) or placebo for 6 months. Prednisolone (20 mg on alternate days) was coadministered in the active treatment group. The mean adjusted between-group difference in forced vital capacity was $4.2 \%$ in favour of cyclophosphamide, which just missed statistical significance $(p=0.08)$. The lung diffusing capacity for carbon monoxide and other outcome measures did not improve. ${ }^{63}$ There was unanimous consensus about the cyclophosphamide dose and duration of treatment to be tailored individually dependent on the clinical condition and response. Potential risks of bone marrow suppression, teratogeneity, gonadal failure and haemorrhagic cystitis must be always considered. ${ }^{82}$

\section{Scleroderma renal crisis}

10. Despite the lack of RCT, experts believe that angiotensinconverting enzyme (ACE) inhibitors should be used in the treatment of scleroderma renal crisis (SRC).

RCT evaluating the efficacy of ACE inhibitors in the treatment of SRC are lacking. Since the first report demonstrating a beneficial effect of ACE inhibitors in two patients with SRC, ${ }^{64}$ numerous case reports and uncontrolled studies have reported on ACE inhibitors in SRC. A prospective analysis of 108 patients with SRC has suggested that patients on ACE inhibitors (captopril in 47 and enalapril in eight) had a significantly better survival rate at 1 year $(76 \%)$ and 5 years (66\%) compared with patients not on ACE inhibitors (15\% at 1 year and $10 \%$ at 5 years, respectively). Treatment with ACE inhibitors was significantly associated with better survival in SRC, after adjustment for age and blood pressure $(p<0.001) .{ }^{65}$ Another prospective uncontrolled study of 145 patients with SRC treated with ACE inhibitors demonstrated survival rates at 5 and 8 years after the onset of SRC of $90 \%$ and $85 \%$, respectively. ${ }^{66}$ In addition, treatment with $\mathrm{ACE}$ inhibitors decreased the need for permanent dialysis. ${ }^{65}{ }^{66}$ Published evidence includes mainly captopril and enalapril.

It is highly unlikely that formal RCT will be conducted in this rare condition with high mortality.

11. Four retrospective studies suggest that steroids are associated with a higher risk of SRC. Patients on steroids should be carefully monitored for blood pressure and renal function.

The impact of steroid use on the development of SRC was evaluated in four retrospective studies involving 544 SSc patients, all suggesting an association between steroid treatment and the occurrence of SRC. ${ }^{67-70} \mathrm{~A}$ case-control analysis showed that $36 \%$ of patients with SRC had received prednisone at a dose of $15 \mathrm{mg} /$ day or more or equivalent within 6 months preceding the onset of SRC, compared with $12 \%$ matched controls (odds ratio 4.4; 95\% CI 2.1 to $9.4 ; \mathrm{p}<0.001$ ).$^{68}$ In another study, recent exposure to corticosteroids was noted in $61 \%$ of SRC patients, and the exposure to corticosteroids during the previous 3 months was associated with a higher risk of SRC (relative risk 6.2; 95\% CI 2.2 to 17.6). ${ }^{70}$ An analysis of the main risk factors for SRC suggested that patients with a high skin score, joint contractures and prednisone use $(\leqslant 10 \mathrm{mg}$ /day in nine out of 10 patients) were at higher risk (43\% versus $21 \%$ of patient without steroids) of SRC. ${ }^{69}$

\section{SSc-related gastrointestinal disease}

12. Despite the lack of specific RCT, experts believe that proton pump inhibitors (PPI) should be used for the prevention of SScrelated gastro-oesophageal reflux disease (GORD), oesophageal ulcers and strictures.

Specific RCT for the efficacy of PPI in patients with SSc are lacking. The efficacy of PPI in the treatment of GORD in a general population is well documented in meta-analyses of RCT. ${ }^{71} 72$

13. Despite the lack of specific RCT, experts believe that prokinetic drugs should be used for the management of SScrelated symptomatic motility disturbances (dysphagia, GORD, early response in satiety, bloating, pseudo-obstruction, etc).

Small RCT involving SSc or CTD patients indicate that the short-term usage of cisapride has a beneficial effect on gastric emptying and lower oesophageal sphincter pressures. ${ }^{73-77}$ However, in many countries cisapride has either been withdrawn or has had limited use as a result of reports about long OT syndrome caused by cisapride, which predisposes to severe arrhythmias.

Long-term efficacy RCT of other prokinetics in SSc were not found. Several non-randomised or uncontrolled studies suggest that prokinetics may improve gastrointestinal signs and symptoms in SSc patients. ${ }^{78-80}$

Several prokinetic drugs have shown beneficial effects in RCT involving patients with other than SSc-related dysmotility disorders or are under evaluation (for review see Hasler ${ }^{83}$ and Karamanolis and $\mathrm{Tack}^{84}$ ). Whether these drugs would be effective in the treatment of SSc-related symptomatic motility disturbances is at present only speculative and needs to be investigated.

14. Despite the lack of specific RCT, experts believe that, when malabsorption is caused by bacterial overgrowth, rotating antibiotics may be useful in SSc.

No RCT regarding the efficacy of antibiotics in the treatment of SSc-related bacterial overgrowth or malabsorption were found.

In general, current treatment of small intestinal bacterial overgrowth is based on empirical courses of broad-spectrum antibiotics such as quinolones or amoxicillin-clavulanic acid. 
Table 2 Comments of the expert committee concerning research questions that did not yield a formal recommendation because of lack of appropriate evidence

\begin{tabular}{ll}
\hline Research question & Comment from the expert committee \\
\hline ACE inhibitors and sartans & \\
$1 \quad$ Do angiotensin receptor antagonists (sartans) & One RCT indicates that losartan may reduce the frequency and severity of \\
have beneficial effects in systemic sclerosis? & RP attacks \\
& Losartan may be recommended for the treatment of RP secondary to SSC
\end{tabular}

Steroids

$1 \quad$ Are steroids beneficial in SSc? The expert opinion is that a low dose of steroids is commonly used for the treatment of inflammatory arthritis in patients with SSc but its efficacy is not substantiated by RCT

HSCT

1 Does HSCT have beneficial effects in SSc? The cumulative phase I-II experience supports the use of HSCT in a selected poor-prognosis subgroup of SSc. Currently, transplantation should be performed only in the context of a RCT

Immunosuppressives

1 Is there any evidence of the beneficial effects of Two RCT with cyclophosphamide have reported efficacy on skin, quality ciclosporine A in SSc? of life and function

2 Is there any evidence of the beneficial effects of Uncontrolled and retrospectively controlled studies with some mycophenolate mofetil in SSc? immunosuppressive regimens (such as azathioprine, mycophenolate mofetil, ciclosporine A) have reported efficacy in selected manifestations of SSc. Their efficacy has to be evaluated further in RCT (see box 1 Research agenda)

3 Is there any evidence of the beneficial effects of of note, experts believe that great caution is necessary when using azathioprine in SSc? cyclosporine because it may decrease renal function and induce hypertension

Other treatments

1 Which drugs are beneficial in subcutaneous Drugs that improve calcinosis are currently lacking calcinosis in SSc?

2 Is there any evidence that NSAID are harmful in Experts believe that NSAID are in general not more harmful in SSc than in SSc? the general population, but formal evidence is lacking. NSAID toxicity in the general population is well recognised

HSCT, haematopoietic stem cell transplantation; NSAID, non-steroidal anti-inflammatory drug; RCT, randomised controlled trial; RP, Raynaud's phenomenon; SSc, systemic sclerosis.

The principles of diagnosis and treatment strategies of this condition have been summarised in a recent excellent review. ${ }^{85}$

\section{DISCUSSION}

The present set of recommendations addresses only a limited number of the most relevant pharmacological treatments for SSc. Many were tested in RCT, although some, even in the absence of RCT, were felt by the expert committee to be indicated for SSc.

As SSc has a heterogeneous clinical course and is an uncommon disease, many treatment options have not yet been able to be appropriately tested. It should be recognised that "absence of evidence for efficacy" does not imply that "efficacy is absent". Indeed, some treatment options that were not translated into recommendations because of lack of evidence were considered important or promising by the expert committee and were included in the research agenda, see box 1 and table 2 .

As a result of the scarcity of high-quality RCT solely involving SSc patients, several recommendations are based on evidence extrapolated from other diseases (such as idiopathic $\mathrm{PAH}$ or GORD). These diseases may differ from SSc-related complications in clinical course and prognosis.

There are also other treatment options for the management of SSc patients, such as physiotherapy, education, new experimental therapies, etc, which were beyond the scope of this project or could not be included because of the lack of expert consensus.

Medications that are disease modifying for SSc in terms of mortality are lacking, and the efficacy of the treatments recommended here is often only modest to moderate. Nevertheless, given no other options, these less than optimal treatments are still worthwhile. This set of recommendations should be helpful to make clinical decisions but should always be used in the context of the patient, clinical judgement and with the balance of efficacy and toxicity in mind.

In view of the heterogeneity of SSc, the complexity of the diagnostic evaluation and the wide array of available treatment options, experts believe that the referral of patients with SSc to a specialised centre should be strongly considered.

Author affiliations: ${ }^{1}$ Department of Rheumatology and Internal Medicine, Medical University of Bialystok, Bialystok, Poland; ${ }^{2}$ Department of Internal Medicine/ Rheumatology, University Hospital Maastricht, Maastricht, The Netherlands;

${ }^{3}$ Rheumatology A Department, RDU, Paris, France; ${ }^{4}$ Department BioMedicine, Division of Rheumatology, University of Florence, Florence, Italy: ${ }^{5}$ Rheumatology Department, UP, Pecs, Hungary; ${ }^{6}$ Rheumatology Department, UCLA, Los Angeles, California, USA; ${ }^{7}$ Rheumatology Department, RFH, London, UK; ${ }^{8}$ Internal Medicine Department, HSL, Paris, France; ${ }^{9}$ Scleroderma Association, FESCA, Harlesden, UK; ${ }^{10}$ Department of Pediatric Rheumatology, Klin Eilbek, Hamburg, Germany; ${ }^{11}$ Rheumatology Department, JLU, Bad Nauheim, Germany; ${ }^{12}$ Rheumatology Department, UMI, Ann Arbor, Michigan, USA; ${ }^{13}$ Rheumatology Department, MUSC, Charleston, Sorth Carolina, USA; ${ }^{14}$ Dermatology Department, USM, Kanazawa, Japan; ${ }^{15}$ Scleroderma Association, FESCA, Budapest, Hungary; ${ }^{16}$ Rheumatology Department, UH, Basel, Switzerland; ${ }^{17}$ Rheumatology Department, SU, Naples, Italy; ${ }^{18}$ Rheumatology Centre Sint Maartenskliniek, Nijmegen, The Netherlands; ${ }^{19}$ Rheumatology Department, JHU, Baltimore, Maryland, USA; ${ }^{20}$ Department of Pediatrics, University of Padua, Padua, Italy

Acknowledgements: The authors wish to thank the European League Against Rheumatism for financial support and Professor Andre Kahan for valuable help with the literature collection.

Funding: This study received financial support from the European League Against Rheumatism.

Competing interests: None.

*EUSTAR co-authors: Lund (F Wollheim, A Scheja); Moskwa (T Nevskaya, L Ananieva, E Nassonov); Paris (Y Allanore, A Kahan); Lille (E Hachulla, D Launay); Manchester

(A Herrick); Newcastle (J van Laar); Geneva (C Chizzolini); Bucharest (C Ciurtin, 
D Opris, R Ionescu, M Capraru); Cluj-Napoca (S Rednic); Zurich (0 Distler); Ankara (I Simsek, A Dinc); Istanbul (M Inanc); Graz (W Graninger); Tubingen (I Kotter); Oslo (JT Gran, 0 Midvedt); Katowice (E Kucharz); Lublin (D Krasowska, M Majdan); Bialystok (S Sierakowski); Coimbra (MJ Salvador, JA Pereira da Silva); Belgrade (N Damjanov); Madrid (P Carreira, P Garcia de la Pena Lefebvre); Debrecen (G Szucs, ZSzekanecz); Praha (R Becvar); Porto (P Pinto); Lisbon (P Coelho); Rijeka (S Novak); Basle (U Walker); Dresden (M Aringer); Gottingen (T Glaenz, CH Neumann, S Emmert); Berlin (M Worm, G Riemekasten); Koln (T Krieg, N Hunzelmann); Mainz (K Steinbrink); Muenster (C Sunderkotter); Stuttgart (S Heitmann); Hamburg (I Foldvari); Bari (F lannone, G Lapadula); Brescia (P Airň); L'Aquila (R Giacomelli); Milan (R Scorza); Genova (M Rizzi, F Indiveri); Rome (V Riccieri); Padova (F Zulian); Ljubljana (B Rozman); Tokyo (K Takehara); Seoul (Jae-Bum Jun); Philadalphia, (C Derk, N Sandorfi, S Jimenez); Johannesburg (M Tikly); Mosul (Saad Alhasani); Tel Hashomer (Y Shoenfeld); Haifa (A Balbir Gurmann).

\section{REFERENCES}

1. Seibold JR, Furst DE, Clements PJ. Why everything (or nothing) seems to work in the treatment of scleroderma. J Rheumatol 1992;19:673-6.

2. Dougados M, Betteridge N, Burmester GR, Euller-Ziegler L, Guillemin F, Hirvonen J, et al. EULAR standardised operating procedures for the elaboration, evaluation, dissemination, and implementation of recommendations endorsed by the EULAR standing committees. Ann Rheum Dis 2004;63:1172-6.

3. Avouac J, Kowal-Bielecka O, Landewe, Chwiesko S, Miniati I, Czirjak L, et al. EULAR Scleroderma Trial and Research group (EUSTAR) recommendations for the Treatment of Systemic Sclerosis: methods of elaboration and results of systematic literature research. Ann Rheum Dis. Published Online First: 28 October 2008. doi: 10.1136/ard.2008.095299

4. Jadad AR, Moore RA, Carroll D, Jenkinson C, Reynolds DJ, Gavaghan DJ, et al. Assessing the quality of reports of randomised clinical trials: is blinding necessary? Control Clin Trials 1996;17:1-12.

5. Shekelle PG, Woolf SH, Eccles M, Grimshaw J. Clinical guidelines: developing guidelines. BMJ 1999;318:593-6.

6. Ettinger WH, Wise RA, Schaffhauser D, Wigley FM. Controlled double-blind trial of dazoxiben and nifedipine in the treatment of Raynaud's phenomenon. Am J Med 1984; $77: 451-6$.

7. Kahan A, Weber S, Amor B, Menkes CJ, Saporta L, Hodara M, et al. Calcium entry blocking agents in digital vasospasm (Raynaud's phenomenon). Eur Heart $J$ 1983;4(suppl C):123-9.

8. Kahan A, Foult JM, Weber S, Amor B, Menkes CJ, Degeorges M. Nifedipine and alpha-1-adrenergic blockade in Raynaud's phenomenon. Eur Heart J 1985;6:702-5.

9. Kahan A, Amor B, Menkes CJ, Weber S, Guerin F, Degeorges M. Nicardipine in the treatment of Raynaud's phenomenon: a randomized double-blind trial. Angiology 1987:38:333-7.

10. Rademaker M, Cooke ED, Almond NE, Beacham JA, Smith RE, Mant TG, et al. Comparison of intravenous infusions of iloprost and oral nifedipine in treatment of Raynaud's phenomenon in patients with systemic sclerosis: a double blind randomised study. BMJ 1989;298:561-4.

11. Rodeheffer RJ, Rommer JA, Wigley F, Smith CR. Controlled double-blind trial of nifedipine in the treatment of Raynaud's phenomenon. N Engl J Med 1983; 308:880-3

12. Thomas MRH, Rademaker M, Grimes SM, MacKay A, Kovacs IB, Cook ED, et al. Nifedipine in the treatment of Raynaud's phenomenon in patients with systemic sclerosis. Br J Dermatol 1987;117:237-41

13. Dziadzio M, Denton CP, Smith R, Howell K, Blann A, Bowers E, et al. Losartan therapy for Raynaud's phenomenon and scleroderma: clinical and biochemical findings in a fifteen-week, randomized, parallel-group, controlled trial. Arthritis Rheum 1999;42:2646-55

14. Thompson AE, Shea B, Welch V, Fenlon D, Pope JE. Calcium-channel blockers for Raynaud's phenomenon in systemic sclerosis. Arthritis Rheum 2001:44:1841-7.

15. Rhedda A, McCans J, Willan AR, Ford PM. A double blind placebo controlled crossover randomized trial of diltiazem in Raynaud's phenomenon. J Rheumatol 1985;12:724-7.

16. Kahan A, Amor B, Menkes CJ. A randomised double-blind trial of diltiazem in the treatment of Raynaud's phenomenon. Ann Rheum Dis 1985;44:30-3.

17. Belch JJ, Capell HA, Cooke ED, Kirby JD, Lau CS, Madhok R, et al. Oral iloprost as a treatment for Raynaud's syndrome: a double blind multicentre placebo controlled study. Ann Rheum Dis 1995;54:197-200.

18. Kyle MV, Belcher G, Hazleman BL. Placebo controlled study showing therapeutic benefit of iloprost in the treatment of Raynaud's phenomenon. $J$ Rheumatol 1992; 19:1403-6.

19. Lau CS, Belch JJ, Madhok R, Cappell H, Herrick A, Jayson M, et al. A randomised, double-blind study of cicaprost, an oral prostacyclin analogue, in the treatment of Raynaud's phenomenon secondary to systemic sclerosis. Clin Exp Rheumatol 1993:11:35-40.

20. McHugh NJ, Csuka M, Watson H, Belcher G, Amadi A, Ring EF, et al. Infusion of iloprost, a prostacyclin analogue, for treatment of Raynaud's phenomenon in systemic sclerosis. Ann Rheum Dis 1988:47:43-7.

21. Wigley FM, Seibold JR, Wise RA, McCloskey DA, Dole WP. Intravenous iloprost treatment of Raynaud's phenomenon and ischemic ulcers secondary to systemic sclerosis. J Rheumatol 1992:19:1407-14.
22. Wigley FM, Wise RA, Seibold JR, McCloskey DA, Kujala G, Medsger TA Jr, et al. Intravenous iloprost infusion in patients with Raynaud phenomenon secondary to systemic sclerosis. A multicenter, placebo-controlled, double-blind study. Ann Intern Med 1994;120:199-206.

23. Yardumian DA, Isenberg DA. Rustin M, Belcher G,.Snaith ML, Dowd PM, et al. Successful treatment of Raynaud's syndrome with iloprost, a chemically stable prostacyclin analogue. Br J Rheumatol 1988;27:220-6.

24. Pope J, Fenlon D, Thompson A, Shea B, Furst D, Wells G, et al. lloprost and cisaprost for Raynaud's phenomenon in progressive systemic sclerosis. Cochrane Database Syst Rev 1998;(2):CD000953. doi: 10.1002/14651858.CD000953.

25. Wigley FM, Korn JH, Csuka ME, Medsger TA Jr, Rothfield NF, Ellman M, et al. Oral iloprost treatment in patients with Raynaud's phenomenon secondary to systemic sclerosis: a multicenter, placebo-controlled, double-blind study. Arthritis Rheum 1998:41:670-7.

26. Black CM, Halkier SA, Rensen L, Belch JJ, Ullman S, Madhok R, et al. Oral iloprost in Raynaud's phenomenon secondary to systemic sclerosis: a multicentre, placebocontrolled, dose-comparison study. Br J Rheumatol 1998;37:952-60.

27. Vayssairat M. Preventive effect of an oral prostacyclin analog, beraprost sodium, on digital necrosis in systemic sclerosis. French Microcirculation Society Multicenter Group for the Study of Vascular Acrosyndromes. J Rheumatol 1999;26:2173-8.

28. Scorza R, Caronni M, Mascagni B, Berruti V, Bazzi S, Micallef E, et al. Effects of longterm cyclic iloprost therapy in systemic sclerosis with Raynaud's phenomenon. A randomized, controlled study. Clin Exp Rheumatol 2001;19:503-8.

29. Badesch DB, Tapson VF, McGoon MD, Brundage BH, Rubin LJ, Wigley FM, et al. Continuous intravenous epoprostenol for pulmonary hypertension due to the scleroderma spectrum of disease. A randomized controlled trial. Ann Intern Med 2000; 132:425-34

30. Korn JH, Mayes M, Matucci Cerinic M, Rainisio M, Pope J, Hachulla E, et al, for the RAPIDS-1 Study Group. Digital ulcers in systemic sclerosis. prevention by treatment with bosentan, an oral endothelin receptor antagonist. Arthritis Rheum 2004:50:3985-93

31. Seibold JR, Denton CP, Furst DE, Matucci-Cerinic M, Mayes MD, Morganti A, et al. Bosentan prevents occurrence but does not speed healing of digital ulcers in patients with systemic sclerosis (SSc). Arthritis Rheum 2005;52(suppl):http://www. abstractsonline.com/viewer/viewAbstractPrintFriendly.asp?CKey $=\{33 F 18 D 9 E-8480-$ 4474-640A-88F04C7721A6\}\&SKey=\{E4435789-ICOA-46A4-AC54634B5E31B449\}\&MKey=\{F5B9F43A-15A0-467D-8458-SDF32518B4E3 $\}$ \&AKey= \{AA45DD66-F113-4CDD-8E62-01A05F613C0D\} (accessed 6 Feb 2009)

32. Seibold JR, Matucci-Cerinic M, Denton CP, Furst DE, Mayes MD, Kramer F, et al. Bosentan reduces the number of new digital ulcers in patients with systemic sclerosis. Ann Rheum Dis 2006;65(suppl II):90.

33. Treinen KA, Louden C, Dennis MJ, Wier PJ. Developmental toxicity and toxicokinetics of two endothelin receptor antagonists in rats and rabbits. Teratology 1999:59:51-9.

34. Medication guide Tracleer (tra-KLEER) tablets. A10509 Tracleer US Outsert.indd 1, (IN-5247/S) Actelion Pharmaceuticals US, Inc. http://www.fda.gov/medwatch/ SAFETY/2004/nov_Pl/Tracleer_Pl.pdf (accessed Jan 2009)

35. van Giersbergen $\mathbf{P L}$, Halabi $\bar{A}$, Dingemanse J. Pharmacokinetic interaction between bosentan and the oral contraceptives norethisterone and ethinyl estradiol. Int J Clin Pharmacol Ther 2006;44:113-18.

36. Channick RN, Simonneau G, Sitbon O, Robbins IM, Frost A, Tapson VF, et al. Effects of the dual endothelin-receptor antagonist bosentan in patients with pulmonary hypertension: a randomised placebo-controlled study. Lancet 2001:358:1119-23.

37. Rubin LJ, Badesch DB, Barst RJ, Galie N, Black CM, Keogh A, et al. Bosentan therapy for pulmonary arterial hypertension. N Engl J Med 2002;346:896-903

38. Humbert M, Barst RJ, Robbins IM, Channick RN, Galiè N, Boonstra A, et al. Combination of bosentan with epoprostenol in pulmonary arterial hypertension: BREATHE-2. Eur Respir J 2004;24:353-9.

39. Barst RJ, Langleben D, Frost A, Horn EM, Oudiz R, Shapiro S, for STRIDE-1 Study Group. Sitaxsentan therapy for pulmonary arterial hypertension. Am J Respir Crit Care Med 2004;169:441-7.

40. Wilkins MR, Paul GA, Strange JW, Tunariu N, Gin-Sing W, Banya WA, et al Sildenafil versus Endothelin Receptor Antagonist for Pulmonary Hypertension (SERAPH) study. Am J Respir Crit Care Med 2005:171:1292-7.

41. Liu C, Chen J. Endothelin receptor antagonists for pulmonary arterial hypertension Cochrane Database Syst Rev 2006;3:CD004434.

42. Galie N, Hinderliter AL, Torbicki A, Fourme T, Simonneau G, Pulido T, et al. Effects of the oral endothelin-receptor antagonist bosentan on echocardiographic and doppler measures in patients with pulmonary arterial hypertension. J Am Coll Cardiol 2003;41:1380-6.

43. Denton CP, Humbert M, Rubin L, Black CM. Bosentan treatment for pulmonary arterial hypertension related to connective tissue disease: a subgroup analysis of the pivotal clinical trials and their open-label extensions. Ann Rheum Dis 2006;65:1336-40.

44. McLaughlin VV. Survival in patients with pulmonary arterial hypertension treated with first-line bosentan. Eur J Clin Invest 2006;36(suppl 3):10-15.

45. Williams MH, Das C, Handler CE, Akram MR, Davar J, Denton CP, et al. Systemic sclerosis associated pulmonary hypertension: improved survival in the current era. Heart 2006;92:926-32.

46. Badesch DB, Abman SH, Simonneau G, Rubin LJ, McLaughlin W. Medical therapy for pulmonary arterial hypertension: updated ACCP evidence-based clinical practice guidelines. Chest 2007:131:1917-28. 
47. Barst RJ, Langleben D, Badesch D, Frost A, Lawrence EC, Shapiro S, et al, STRIDE-2 Study Group. Treatment of pulmonary arterial hypertension with the selective endothelin-A receptor antagonist sitaxsentan. J Am Coll Cardiol 2006;47:2049-56.

48. Langleben D, Brock T, Dixon R, Barst R, STRIDE-1 study group. STRIDE 1: effects of the selective ETA receptor antagonist, sitaxsentan sodium, in a patient population with pulmonary arterial hypertension that meets traditional inclusion criteria of previous pulmonary arterial hypertension trials. J Cardiovasc Pharmacol 2004;44(suppl):S80-S84.

49. Seibold JR, Langleben D, Badesch D, Naeije R, Galié N, Barst RJ. Sitaxsentan, a selective endothelin-a receptor antagonist, improves exercise capacity in PAH associated with CTD Ann Rheum Dis 2006;65(suppl II):522.

50. Highland KB, Strange C, Girgis R, Black C. Comparison of sitaxentan and bosentan in pulmonary arterial hypertension associated with connective tissue diseases. Ann Rheum Dis 2006;65(suppl II):393.

51. Benza RL, Mehta S, Keogh A, Lawrence EC, Oudiz RJ, Barst RJ. Sitaxsentan treatment for patients with pulmonary arterial hypertension discontinuing bosentan. $J$ Heart Lung Transplant 2007;26:63-9.

52. Galie N, Ghofrani HA, Torbicki A, Barst RJ, Rubin LJ, Badesch D, et al, Sildenafil Use in Pulmonary Arterial Hypertension (SUPER) Study Group. Sildenafil citrate therapy for pulmonary arterial hypertension. N Engl J Med 2005;353:2148-57.

53. Simonneau G, Burgess G, Parpia T, Badesch D. Sildenafil improves exercise ability and hemodynamics in patients with pulmonary arterial hypertension associated with connective tissue disease. Ann Rheum Dis 2005;64(suppl III):109.

54. Sitbon 0, Humbert M, Nunes H, Parent F, Garcia G, Hervé P, et al. Long-term intravenous epoprostenol infusion in primary pulmonary hypertension: prognostic factors and survival. J Am Coll Cardiol 2002:40:780-8.

55. McLaughlin VV, Shillington A, Rich S. Survival in primary pulmonary hypertension: the impact of epoprostenol therapy. Circulation 2002;106:1477-82.

56. Food and Drug Administration. Drug approval package: flolan (epoprosteno sodium) injection. 21 November 2001. http://www.fda.gov/cder/foi/nda/2000/20444S003 Flolan.htm (accessed Jan 2009).

57. Simonneau G, Barst RJ, Galie N, Naeije R, Rich S, Bourge RC, et al, Treprostinil Study Group. Continuous subcutaneous infusion of treprostinil, a prostacyclin analogue, in patients with pulmonary arterial hypertension: a double-blind, randomized, placebo-controlled trial. Am J Respir Crit Care Med 2002;165:800-4.

58. Olschewski H, Simonneau G, Galie N, Higenbottam T, Naeije R, Rubin LJ, et al, Aerosolized lloprost Randomized Study Group. Inhaled iloprost for severe pulmonary hypertension. N Engl J Med 2002;347:322-9.

59. Oudiz RJ, Schilz RJ, Barst RJ, Galie N, Rich S, Rubin LJ, et al. Treprostinil Study Group. Treprostinil, a prostacyclin analogue, in pulmonary arterial hypertension associated with connective tissue disease. Chest 2004;126:420-7.

60. van den Hoogen FH, Boerbooms AM, Swaak AJ, Rasker JJ, van Lier HJ, van de Putte LB. Comparison of methotrexate with placebo in the treatment of systemic sclerosis: a 24 week randomized double-blind trial, followed by a 24 week observational trial. Br J Rheumatol 1996:35:364-72.

61. Pope JE, Bellamy N, Seibold JR, Baron M, Ellman M, Carette S, et al. A randomized, controlled trial of methotrexate versus placebo in early diffuse scleroderma. Arthritis Rheum 2001:44:1351-8.

62. Tashkin DP, Elashoff R, Clements PJ, Goldin J, Roth MD, Furst DE, et al, Scleroderma Lung Study Research Group. Cyclophosphamide versus placebo in scleroderma lung disease. N Engl J Med 2006;354:2655-66.

63. Hoyles RK, Ellis RW, Wellsbury J, Lees B, Newlands P, Goh NS, et al. A multicenter, prospective, randomized, double-blind, placebo-controlled trial of corticosteroids and intravenous cyclophosphamide followed by oral azathioprine for the treatment of pulmonary fibrosis in scleroderma. Arthritis Rheum 2006;54:3962-70.

64. Lopez-Ovejero JA, Saal SD, D'Angelo WA, Cheigh JS, Stenzel KH, Laragh JH. Reversal of vascular and renal crises of scleroderma by oral angiotensin-convertingenzyme blockade. N Engl J Med 1979;300:1417-19.
65. Steen VD, Costantino JP, Shapiro AP, Medsger TA Jr. Outcome of renal crisis in systemic sclerosis: relation to availability of angiotensin converting enzyme (ACE) inhibitors. Ann Intern Med 1990;113:352-7.

66. Steen VD, Medsger TA Jr. Long-term outcomes of scleroderma renal crisis. Ann Intern Med 2000;133:600-3.

67. Helfrich DJ, Banner B, Steen VD, Medsger TA Jr. Normotensive renal failure in systemic sclerosis. Arthritis Rheum 1989:32:1128-34.

68. Steen VD, Medsger TA Jr. Case-control study of corticosteroids and other drugs that either precipitate or protect from the development of scleroderma renal crisis. Arthritis Rheum 1998:41:1613-19.

69. DeMarco PJ, Weisman MH, Seibold JR, Furst DE, Wong WK, Hurwitz EL, et al. Predictors and outcomes of scleroderma renal crisis: the high-dose versus low-dose D-penicillamine in early diffuse systemic sclerosis trial. Arthritis Rheum 2002;46:2983-9.

70. Teixeira L, Mouthon L, Mahr A, Agard C, Cabane J, Guillevin L, for the Groupe Français de Recherche sur la Sclérodermie. Scleroderma renal crisis: presentation, outcome and risk factors based on a retrospective multicenter study of 50 patients. Arthritis Rheum 2006;54(suppl):s743.

71. Chiba N, De Gara CJ, Wilkinson JM, Hunt RH. Speed of healing and symptom relie in grade II to IV gastroesophageal reflux disease: a meta-analysis. Gastroenterology 1997:112:1798-810.

72. van Pinxteren B, Numans ME, Bonis PA, Lau J. Short-term treatment with proton pump inhibitors, $\mathrm{H} 2$-receptor antagonists and prokinetics for gastro-oesophageal reflux disease-like symptoms and endoscopy negative reflux disease. Cochrane Database Syst Rev 2006;3:CD002095

73. Horowitz M, Maddern GJ, Maddox A, Wishart J, Chatterton BE, Shearman DJ. Effects of cisapride on gastric and esophageal emptying in progressive systemic sclerosis. Gastroenterology 1987;93:311-15.

74. Wehrmann T, Caspary WF. Effect of cisapride on esophageal motility in healthy probands and patients with progressive systemic scleroderma. Klin Wochenschr 1990:68:602-7.

75. Kahan A, Chaussade S, Gaudric M, Freitag B, Amor B, Menkes CJ, et al. The effect of cisapride on gastro-oesophageal dysfunction in systemic sclerosis: a controlled manometric study. Br J Clin Pharmacol 1991;31:683-7.

76. Limburg AJ, Smit AJ, Kleibeuker JH. Effects of cisapride on the esophageal moto function of patients with progressive systemic sclerosis or mixed connective tissue disease. Digestion 1991:49:156-60.

77. Wang SJ, La JL, Chen DY, Chen YH, Hsieh TY, Lin WY. Effects of cisapride on oesophageal transit of solids in patients with progressive systemic sclerosis. Clin Rheumatol 2002:21:43-5.

78. Fiorucci S, Distrutti E, Gerli R, Morelli A. Effect of erythromycin on gastric and gallbladder emptying and gastrointestinal symptoms in scleroderma patients is maintained medium term. Am J Gastroenterol 1994:89:550-5.

79. Verne GN, Eaker EY, Hardy E, Sninsky CA. Effect of octreotide and erythromycin on idiopathic and scleroderma-associated intestinal pseudoobstruction. Dig Dis Sci 1995; 40:1892-901.

80. Soudah HC, Hasler WL, Owyang C. Effect of octreotide on intestinal motility and bacterial overgrowth in scleroderma. N Engl J Med 1991:325:1461-7.

81. Arakawa H, Yamasaki M, Kurihara Y, Yamada H, Nakajima Y. Methotrexate induced pulmonary injury: serial CT findings. J Thorac Imaging 2003;18:231-6.

82. Lynch JP III, McCune WJ. Immunosuppressive and cytotoxic pharmacotherapy for pulmonary disorders. Am J Respir Crit Care Med 1997;155:395-420.

83. Hasler WL. Pharmacotherapy for intestinal motor and sensory disorders. Gastroenterol Clin North Am 2003:32:707-32.

84. Karamanolis G, Tack J. Promotility medications-now and in the future. Dig Dis 2006:24:297-307.

85. Gasbarrini A, Lauritano EC, Gabrielli M, Scarpellini E, Lupascu A, Ojetti V, et al. Small intestinal bacterial overgrowth: diagnosis and treatment. Dig Dis 2007;25:237-40. 